\title{
Three point six nine one
}

\section{Bernard Perbal ${ }^{1,2}$}

Published online: 20 August 2019

(C) The International CCN Society 2019

This year, the Journal of Cell Communication and Signaling Impact Factor reached 3.691.

A good surprise for some of us,

A well deserved progression for others,

Another step towards worldwide recognition indeed.

In any case, this good news gives me the opportunity to sincerely acknowledge authors, reviewers, and editors, who participated directly or indirectly to this achievement. I am anticipating that we can go along this way together and gather many more points...

\section{The impact factor}

The significance of the Thomson Reuters Impact factor (IF), published every year in the journal citation report (JCR) has been addressed in these columns a few years ago (Perbal 2015). It is still the source of intense debate although the general acceptance is in favor of the IF reflecting the scientific quality of the articles published in journals with high IF.

Considering the value given by many institutions to the IF, it is of interest to analyze the variations in the JCCS IF with respect to the evolution of JCCS scientific content during the same period of time.

First of all, the metrics collected for the years 2016 to 2018 inclusive show a marked $40 \%$ increase of articles downloaded in 2017, confirmed in 2018 and found to rise again by 6 points over the first semester of 2019.

Although the significance of the download numbers is not easy to estimate, it is tempting to interpret the progression of these values as reflecting a widening readership.

Bernard Perbal

bperbal@gmail.com

International CCN Society, Nice, France

2 EDA SUD-EST, Marseille 13004, France
We must keep in mind that IF and readership do not necessarily match and that, in any case, an increasing JCCS readership is quite satisfactory.

\section{Topics and quality}

The variety of topics covered by JCCS is illustrated by the significant progression in the number of articles dealing with several different aspects of cellular signaling and cell communication.

The scientific quality of the manuscripts accepted for publications after a critical review process, was a key pillar to the increasing citation index of JCCS.

A significant increase in the number of JCCS article citations occurred between year 2015 and 2018 with a $41 \%$ rise and a corresponding increase of $19 \%$ in citable items. ${ }^{1}$

The progress was even more striking when we compared the rise of citable elements $(9.6 \%)$ and article citations (60\%) that occurred between 2017 and 2018. These figures suggest that the quality of the articles published in 2018 improved whereas the rise of article citations was not the sole result of a greater number of published manuscripts.

Even though JCCS was created and devoted to be the official journal of the International CCN Society (ICCNS), it was not meant to exclusively publish $\mathrm{CCN}$-related manuscripts.

Indeed, in addition to providing "comprehensive information related to the field of the CCN genes and proteins", the ICCNS also aims to "provide a forum for discussion and interaction "and "to promote the dissemination of scientific information through the publication of the Journal of Cell Communication and Signaling".

A close examination of the article categories published over the past 3 years revealed that only 32\%, $18 \%$ and $34 \%$ of the manuscripts published between 2016 and 2018,

\footnotetext{
${ }^{1}$ For a definition of citable elements by Thomson Reuters see Davis P. (2016) "Their guidelines include such characteristics as whether a paper has a descriptive title, whether there are named authors and addresses, whether there is an abstract, the article length, whether it contains cited references, and the density those cited references
} 
respectively, reported findings regarding $\mathrm{CCN}$ genes and protein biology. Their relative contribution to the total numbers of citations was $42 \%, 20 \%$, and $40 \%$, respectively.

\section{Where do we go next?}

We at JCCS, follow a very strict reviewing protocol prior to manuscript acceptance. Along this line we are faced with the risk of "data manipulation" and "manuscript retraction" (Perbal 2017).

The increasing number of manuscript retractions that we have witnessed over the past decade is raising doubts about the reviewing process that should trigger a very thorough examination of the data included in submitted manuscripts. We understand that it is extremely difficult, if not quasi-impossible, for someone who is not directly involved in running the experiments, to uncover falsified data, to find out conflicting evidence not provided, or to determine that protocols were not followed...

Nevertheless, editors and reviewers should not underestimate the responsibility that they have when they write a report.

We are ourselves are presently experiencing difficulties to make researchers from scientifically-developing countries understand that publication of a data cannot rely on a weak demonstration, or lack of good controls.

This can be explained and corrected with time.

We are happy to help and when it works, happy to see quite good reports from non-occidental countries make their way to publication in an international renowned journal such as JCCS, and to be cited.

Unfortunately, different scales of scientific data manipulation are also being uncovered in countries where ethics and deontology have profound roots.

Dozens of manuscripts reporting the use of "cardiac stem cells" have been retracted last year (Taylor 2018), and genetic publications have been retracted at a particularly high rate (Hou 2019).

Worldwide examples of unacceptable scientific behavior that are covered by administrations and politicians have been reported in the press (Akst 2018; Jouan 2018). Scientific misconduct is voluntary ignored and culprits are protected, while whistle blowers do not get the legal protection they deserve.

Recent news about data manipulation by the AveXis subsidiary of Novartis shed light on a higher level of unacceptable behavior (Florko 2019), even if it is said that the data manipulation "does not affect" the applicability in humans. The approval of spinal muscular atrophy treatment with Zolgensma by the FDA was based on falsified scientific evidence provided by scientists who ignored the meaning of ethics and deontology.

Scientific publishing is meant to report data that can be used as a solid basis to other future investigations that in turn are expected to help provide a better standard of life to all human beings.

There is no room for cheaters and data manipulators of any kind.

The example of medical and scientific misconducts that drove thousands of humans to HIV-induced death should not be reproduced. There is no room for administration-covered malfeasance that can turn into a wide medical disaster.

All types of scientific misconduct must be fought and scientific journals should make sure that the data they publish is based on solid evidence.

This is our motto, whatever the consequences on the JCCS impact factor.

Acknowledgments Tahnks to Annick and Herman for proofreading.

\section{References}

Akst J (2018) Report: former CNRS president guilty of fraud, The Scientist

Davis P (2016) Citable Items: The Contested Impact Factor Denominator. The scholarly kitchen, Feb 10, 2016 https://scholarlykitchen.sspnet. org/2016/02/10/citable-items-the-contested-impact-factordenominator/

Florko N (2019) Senators blast Novartis over data manipulation before approval of Zolgensma. STAT, August 9th

Hou CY (2019) Genetics articles retracted at higher rate than other disciplines. The Scientist Jul 26, 2019 https://www.the-scientist.com/ news-opinion/genetics-articles-retracted-at-higher-rate-than-otherdisciplines-66206

Jouan A (2018) Le rapport accablant contre l'ex-patronne du CNRS L'Express, Ocotber 8th

Perbal B (2015) What kind of a life for a scientific journal? J Cell Commun Signal Sep 9(3):201-206. https://doi.org/10.1007/ s12079-015-0306-6 Epub 2015 Sep 3

Perbal A (2017) The disastrous boomerang effects of "citation mania". J Cell Commun Signal 11(3):291-295

Taylor AP (2018) Dozens of retractions requested for heart stem cell studies The Scientist Oct 15

Publisher's note Springer Nature remains neutral with regard to jurisdictional claims in published maps and institutional affiliations. 